\title{
Making an Impact: An Initial Review of U.S. Sport League Corporate Social Responsibility Responses During COVID-19
}

\author{
Danielle K. Smith \\ Jonathan Casper \\ University of North Carolina \\ North Carolina State University \\ at Chapel Hill
}

COVID-19 has brought about an unprecedented time where a majority of major American sporting organizations have ceased competition. Corporate social responsibility (CSR) actions, historically an avenue for sport organizations to positively impact society, provide a compelling avenue of study during this time. While researchers have observed the role of CSR and crisis communication when the crisis arises from within the organization, there is a need to understand CSR shifts and responses when the crisis is on a societal level. This commentary examines efforts of major U.S. sport league CSR programs (National Basketball Association/Women's National Basketball Association, National Football League, Major League Baseball, Major League Soccer, and National Hockey League), starting in mid-March when the majority of organizations ceased competition. Data were gathered using a mixed-methods approach of qualitative interviews, secondary research, and social media sentiment analysis. Key findings included the emergence of two different approaches to CSR communication strategies among U.S. sport leagues as well as three clear themes of COVID-19related communication: educate, assist, and inspire. In addition, this commentary provides an initial glance at consumer response to CSR programs, showing both positive and negative sentiment trends.

Keywords: crisis communication, CSR, social sentiment

Sport leagues play a critical role in the sport ecosystem, often driving policy and governance for teams, athletes, and associated agencies. In the United States, the structure of professional sport lends itself to cohesive communication strategies. While there are many organizational entities integrated in the U.S. sport network, we often see sport leagues and league commissioners responsible for fan communication 
as they are viewed as a central source of information for the entire sport ecosystem. This commentary will examine initial U.S. professional sport league communication efforts driven by their respective corporate social responsibility (CSR) arms during COVID-19. Specifically, it will analyze and discuss three areas of sport communication: the role that CSR plays during crisis communication, how U.S. sport league CSR programs reacted and structured their CSR communications, and how fans feel about their league's respective communication outreach.

The data for this commentary were gathered using qualitative interviews with select league CSR leaders, secondary research on league communication programs, and social media sentiment analysis (SA). These data provide an initial glance at the ways sport leagues are using CSR platforms to communicate with and inspire action from their most important constituent, the fans. Given the timing and availability of league personnel, we conducted in-depth interviews with two sport league CSR leaders, which provide a behind-the-scenes glimpse into organizational decision making not found in external communications. Todd Jacobson, senior vice president of social responsibility for the National Basketball Association (NBA), and Melanie LeGrande, vice president of social responsibility for Major League Baseball (MLB), offered their professional perspective and insights. The focus for the interviews centered around their role within their respective organizations, the organizational response strategy to COVID-19, the role that CSR holds for fan communications, and the impact of COVID-19 on their current programs and fan outreach. Interviews received institutional review board approval from North Carolina State University. To provide further insight into other league responses, we used secondary research from league websites and social media accounts to analyze overall CSR organizational efforts specific to COVID-19. Finally, to integrate fan perceptions, we conducted a social media SA to ascertain how fans were responding to league CSR platforms via social media. Using the Crimson Hexagon analytics platform, NBA and Major League Soccer (MLS) CSR Twitter handles were analyzed during three distinct timeframes relevant to this commentary: prior to COVID-19, immediately following major COVID-19 impacts in the United States, and for a period after the initial COVID-19 effect.

\section{Role of CSR and Communication Strategies During a Crisis}

Virtually all organizations within the sport industry, broadly defined, have adopted CSR programs (Babiak \& Wolfe, 2009), and professional sport leagues, teams, and athletes are influential agents in our society when considering economic and cultural perspectives (Kern, 2000). Given the role CSR plays, particularly in sports, its importance to the impact of sport overall is an important aspect of study when discussing COVID-19. For example, the passion and identification as a sport fan can benefit communities as a whole by encouraging and strengthening community integration (Wakefield \& Wann, 2006). As sport CSR programs clearly work to foster and strengthen sport fan communities, the intersection of sport league CSR communications plays a critical role during our current societal times.

Despite the frequency of sport crises, we lack knowledge of how sport organizations should react in a systematic way when the crisis originates on a 
macrolevel. The societal impact and associated response of sport organizations during COVID-19 will provide evidence of new response strategies, in which apologies and mitigation may be replaced with information sources, action-based programming, and storytelling as a means for increasing positive sentiment and a spirit of togetherness, already prevalent among sport fans.

\section{Sport League CSR Crisis Response Strategies During COVID-19}

Sport fandom is a global unifier, used historically as a social platform to impact broader societal change. For example, one out of every seven people in the world has access to watch NBA games, accounting for just one of the professional sport leagues (T. Jacobson, personal interview, April 28, 2020). There is a variety of literature on sport entities dealing with crises; however, the crises studied are often initiated by the organization or athlete themselves (e.g., Tiger Woods, L.A. Clippers, etc.).

How are sport organizations shaping their fan responses to the COVID-19 crisis? Before going into specific strategies, it is important to note that CSR groups are just one $\operatorname{cog}$ in a league-wide response. Responses and associated programs encompass full collaboration across internal groups. Leaders of sport league CSR organizations see themselves as aggregating efforts across the whole ecosystem of their sport, both with internal league functions (e.g., marketing and sponsorship) to associated external entities (e.g., teams and athletes). The response therefore is a fully integrated communication effort, with input and aggregation from all competencies and constituents. While CSR groups are focused on their specific programs and outreach, it is important to keep in mind the totality of the groups involved in these efforts.

\section{Organizational Communication Strategies}

It is evident that two distinct strategies emerged in response to the COVID-19 health crisis (see Figure 1). These strategies include either creating entirely new umbrella communication programs or integrating COVID-19-related efforts into existing CSR programs and communication vehicles. To better understand the nuances of these distinct strategies, interviews with Jacobson and LeGrande helped shed light upon each of the two communication responses.

The NBA Senior Vice President of Social Responsibility, Todd Jacobson, discussed the need to aggregate a variety of new and existing programs in response to the pandemic. When the NBA went on hiatus in mid-March, the first thing the NBA asked themselves was, "What can we do to utilize our global platform to have an impact and be as helpful as possible during this time?" (T. Jacobson, personal interview, April 28, 2020). The NBA, together with the Women's National Basketball Association, G-League, 2K League, and Basketball Africa League swiftly created a new community and social engagement initiative called NBA Together, displaying a collaborative global response. This new platform now headlines the NBA's digital assets and communication vehicles. MLS took a similar approach in launching MLS Unites in response to COVID-19. The program was 


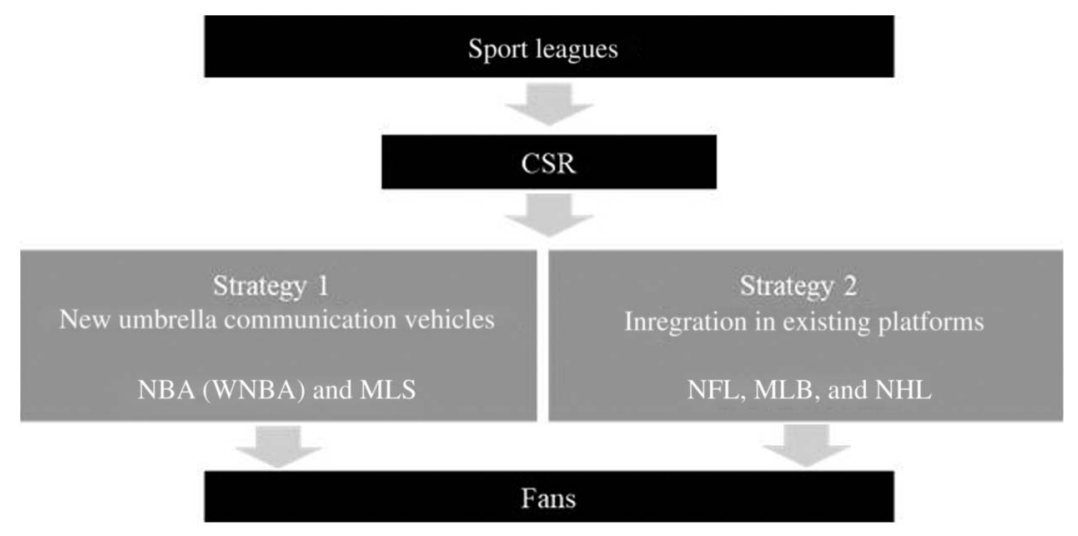

Figure 1 - CSR COVID-19 communication strategies. Note: $\mathrm{CSR}=$ corporate social responsibility; NBA $=$ National Basketball Association; $\mathrm{MLB}=$ Major League Baseball; MLS $=$ Major League Soccer; NFL $=$ National Football League; NHL = National Hockey League.

launched in conjunction with the MLS Players Association to highlight the efforts that players, coaches, clubs, and the league are making to address the COVID-19 pandemic (MLS, 2020).

The MLB, the National Football League (NFL), and the National Hockey League took a slightly different fan communication approach to COVID-19 CSR efforts. Rather than create a new communication platform, they used existing assets and programs to communicate their efforts to help their respective fan communities. LeGrande, with MLB CSR, stated that the needs of their constituents existed before COVID-19, and programs they already had in place had structure and equity; therefore, rather than creating new programs, they focused on shifting implementation techniques and exhibiting urgency in their response (M. LeGrande, personal interview, May 8, 2020). MLB used their existing CSR platforms, such as Healthy Relationships Community Grants, to provide resources during COVID-19 (M. LeGrande, personal interview, May 8, 2020). Healthy Relationships, which supports domestic violence initiatives, is especially important during COVID-19 given the higher risk for domestic abuse at home (Stanley, 2020). The NFL used a national platform, the NFL Draft, to raise funds and awareness of organizations fighting to combat COVID-19, whereas the National Hockey League used virtual tools to offer their existing Future Goals program to youth hockey fans. By using existing platforms, these organizations are capitalizing on equity and structure that are already built, and just shift the focus of efforts to specifically address the unique societal situation of COVID-19.

\section{CSR Focus Themes During COVID-19}

Based on the interviews conducted, and supplemental secondary research, three key themes emerged across U.S. sport league CSR programs during the COVID-19 crisis time frame: educate, assist, and inspire. 


\section{Educate}

Educate is perhaps the most prevalent theme and takes on distinct elements within CSR communication responses. Most relevant is the education role in which sport leagues see themselves in communicating nonsport-related health facts. Given the unique relationship that leagues have with identified sport fans, we know that organizations can have an impact on sport fan behaviors. CSR groups used this influence as rationale for providing COVID-19 health information. The Know Your Facts component of NBA Together started with an almost immediate response, providing COVID-19-related information and resources for NBA fans to access (T. Jacobson, personal interview, April 28, 2020). In the first 2 weeks of launching the program, the Know Your Facts PSAs (public service announcements) were viewed more than 53 million times, indicating a desire from fans to view this content (T. Jacobson, personal interview, April 28, 2020). It then evolved to address areas such as mental health, which is a critical need during COVID-19. Similarly, MLB and MLS provided fans with health-related resources. Per LeGrande, the MLB league is seen as a trusted source both internally and externally, an important factor in MLB deciding to include COVID-19-related health facts within their owned assets for fans to access. Even nonsport entities see the value that sport leagues can have on educating society. LeGrande noted that the Centers for Disease Control and Prevention (CDC) contacted MLB asking them to add additional information to their already existing health facts around face coverings and other pertinent health updates (M. LeGrande, personal interview, May 8, 2020). Nodding to the influence that sport leagues have on their fans, MLS incorporated players and influential fans, such as Robbie Keane and Austin FC's Matthew McConaughey, to provide contextually relevant information in a way that identified sport fans may better receive (MLS, 2020).

Educate is also integrated into existing program elements of many CSR platforms. Social distancing and isolation has affected all sport fans, particularly youth, as approximately 39 million U.S. and Canadian school-aged students are learning at home (Moran, 2020). In the absence of in-person school, youth sports, and events, sport leagues placed an emphasis on digital manifestations of existing programs. MLB and the National Hockey League are looking to increase the reach of their science, technology, engineering, and mathematics-focused efforts. The NBA launched the Jr. NBA Home Series, a virtual version of NBA Math Hoops, and hosted a virtual Jr. NBA Leadership Conference for parents and youth coaches throughout the world, which generated over 969,000 views across@JrNBA Facebook, YouTube, and Twitter (T. Jacobson, personal interview, April 28, 2020). Through the NFL's Play 60 program, the league has made resources available digitally to keep kids moving and active during a time of shelter-in-place regulations. According to LeGrande with MLB, these educational programs are critical for fans, particularly youth fans, now more than ever (M. LeGrande, personal interview, May 8, 2020).

\section{Assist}

Assist is the next theme derived from analyzing sport league CSR efforts. As there is a relationship between identified sport fans and their willingness to participate in 
socially responsible community programs (Zhang \& Surujlal, 2015), it is not a surprise that sport leagues have focused on communication that elicits action from fans. For the NFL, the Draft-a-Thon was prominently featured during the virtual NFL draft broadcast, with continued communication support in the 2 weeks following the broadcast event (NFL, 2020). NBA Together incorporated a portion of their response efforts to Acts of Caring, focused on spotlighting organizations providing vital services (e.g., food insecurity and blood donation) and connecting fans to ways they can give back and contribute in their communities. In addition to the already planned Healthy Community Relationships grants, MLB is supporting Feeding America and Meals on Wheels (M. LeGrande, personal interview, May 8, 2020). Highlighting the ways in which sport leagues are assisting their fan communities, as well as ways in which fans themselves can assist in COVID19 relief efforts, is a clear communication thematic that we believe will continue into the near future. It is important to note that assist goes beyond health-related communications and extends to the economic impact which COVID-19 has had, both on individuals in our society (e.g., food insecurity) and business enterprises (e.g., small businesses).

\section{Inspiration}

Finally, sport leagues see themselves as a source of inspiration for hope and positivity. The U.S. sport leagues analyzed are all using their voices and the reach of their digital assets to share stories from their entire sport ecosystems. MLS, through MLS Unites, uses their platform as a celebration communication tool, sharing stories about donations, health care workers, and inspirational stories (MLS, 2020). Similarly, MLB sees themselves a means to inspire their fans, touting stories of MLB venues used for health care and food support (M. LeGrande, personal interview, May 8, 2020).

Given this empirical evidence, we posit an extension to Coombs and Holladay's (2002) organizational approach to crisis management communication (see Figure 2). Rather than mitigation communication strategies to help the organization get out of a particular crisis to minimize negative impact to the firm, we see additional mitigation strategies that may be more relevant for the current COVID-19 sport climate. The desired result is the same, with sport organizations intending to create positive
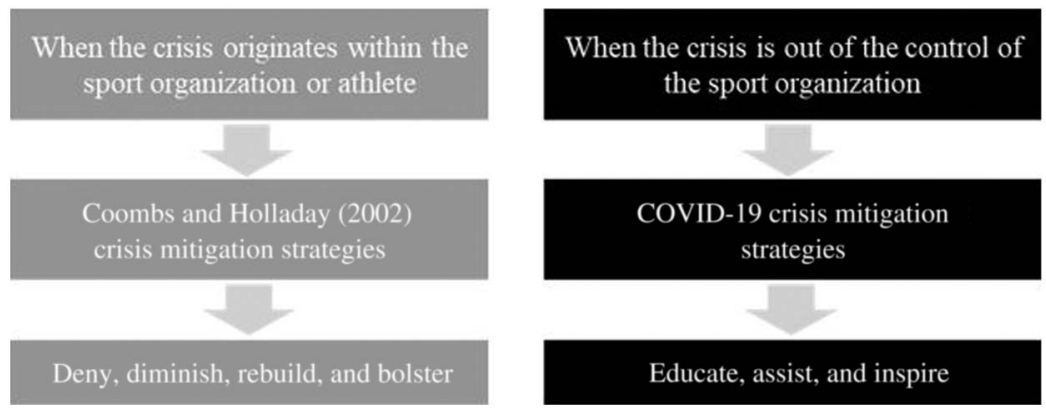

Figure 2 - Crisis mitigation communication strategies. 
feelings and positive business outcomes; however, the communication approach is quite different. With the genesis of COVID-19 falling outside of the organization itself, sport leagues are using different strategies to guide leagues through this particular crisis and continue a connection to fans.

\section{Fan Sentiment}

While it is important to understand the communication strategies employed by sport league CSR groups, it is equally critical to understand the fan response. The growing usage of social media increases the possibility of using digital tools to explain consumer feelings and sentiment. As sport evokes strong emotions among fans, SA can provide insight into how people respond, in real time, to highly emotional events (Gratch et al., 2015). Previous research has used SA to ascertain emotional response, showing the potential of these data for addressing important questions around human emotion (Gratch et al., 2015).

An analysis of Twitter engagements was performed using the social media analytics platform Crimson Hexagon ForSight. This tool analyzes words to determine how consumers are feeling around the associated content. For the purpose of this commentary, and in an attempt to isolate other sporting factors such as a cessation of competition, we used two league CSR-specific Twitter accounts: NBA Cares and MLS Works. Other leagues discussed in this commentary do not employ CSR-specific Twitter accounts and therefore are not included in this component of our analysis.

The NBA Cares and MLS Works accounts were analyzed during three distinct time periods of sport league CSR's response to COVID-19. The first period used was 3 weeks prior to major announcements and societal changes in the United States, February 16, 2020, through March 7, 2020. The next period used for analysis was the week in which most major U.S. sport leagues announced competition hiatus with more broad shelter-in-place communication, March 11, 2020 through March 18, 2020. Finally, we analyzed the period following initial discussions announcements, March 19, 2020 through April 4, 2020. It should be noted that MLS outlined an 8-week competition suspension on March 19, although there was press discussion prior to that time period. For comparison purposes, similar date ranges were used despite a slight difference in the timing of league communications (see Table 1).

\section{Table 1 Twitter Sentiment Analysis}

\begin{tabular}{lccccccc}
\hline & \multicolumn{3}{c}{ NBA Cares } & & \multicolumn{3}{c}{ MLS Works } \\
\cline { 2 - 4 } \cline { 6 - 8 } Time period & $\mathbf{1}$ & $\mathbf{2}$ & $\mathbf{3}$ & & $\mathbf{1}$ & $\mathbf{2}$ & $\mathbf{3}$ \\
\hline Positive (\%) & 44 & 20 & 23 & & 28 & 19 & 51 \\
Neutral (\%) & 55 & 76 & 76 & & 71 & 81 & 48 \\
Negative (\%) & 1 & 4 & 1 & 1 & $<1$ & 1 \\
\hline
\end{tabular}

Note. Time frame 1 = pre-COVID-19, February 16, 2020 to March 7, 2020; Time frame $2=$ week of competition hiatus announcements, March 11, 2020 to March 18, 2020; Time frame 3=post-initial COVID-19 communication, March 19, 2020 to April 4, 2020. NBA = National Basketball Association; MLS = Major League Soccer. Crimson Hexagon ForSight, 2020. 
The effect of this communication strategy is evident in fans' responses to league CSR social channels. One positive theme seen from MLS fans is gratitude toward their continued support of fighting the pandemic and other causes, evident from text used within social engagement (e.g., thank you). As presented in Table 1, results showed a notable increase in positive fan sentiment starting with a baseline of $28 \%$ during the first period, a decrease to $19 \%$ during the second time period, and finally, a rise to $51 \%$ positive sentiment for the most recent period analyzed. NBA fans seemed to respond positively as well, noting the ability for fans to interact with players using the hashtag \#NBA Together, which generated over 938M video views and 90M actions as of May 28, 2020 (T. Jacobson, personal interview, April 28, 2020). Although fans continued to show gratitude for all that the NBA is doing to support those affected by COVID-19, others still expressed that they felt the NBA was not doing enough. Positive sentiment of NBA Cares' Twitter followers was positive pre-COVID with 44\%, likely driven by an influx of positive engagement during NBA All-Star. Sentiment dropped during the hiatus announcement to $20 \%$, and slightly increased to $23 \%$ during the recent time period. While the exact cause of the sentiment decrease is unknown, this may be due to the overall sadness and disappointment of NBA competitions being in hiatus. Given the way the NBA structured the NBA Together program, social content was primarily posted on NBA channels and then shared via the NBA Cares site, which could also account for the decrease in sentiment. As MLS and the NBA continue to use social media to communicate their CSR efforts, positive sentiment should continue to rise.

\section{Conclusion and Implications}

With sport competition in hiatus, CSR is seen as a nucleus of noncompetition communication, evident from this scholarly review. When a crisis originates on a macrolevel outside of organizations themselves (e.g., COVID-19), we posit that organizations integrate additional crisis communication responses, primarily to inspire, assist, and educate, which differs from traditional crisis mitigation strategies such as deny, diminish, rebuild, and bolster. Sport leagues clearly chose two different paths of structuring their communication responses, shown by creating entirely new platforms (e.g., NBA Together) with others integrating COVID-19 efforts under their existing CSR efforts (e.g., MLB). While it is early to speculate about comprehensive fan responses, initial analysis shows varied effects in how fans feel in response to league CSR social media communications.

As competition resumes and COVID-19 outcomes shift, it will be critical for researchers to investigate and understand the long-term impact of CSR program efforts during this time, the longevity of these programs, and fan response. As sport resumes, the education theme will likely shift from broad health related facts to spectator-specific information. Sport leagues have an obligation to educate fans on proper social distancing while at stadiums, arenas, and other social gatherings. We also see a likely continuation of virtual education programming, as leagues have an opportunity to reach their fans, specifically youth, in sport-related programming when they might not be able to attend in person. For the theme "Assist," while the initial focus was on immediate community needs, leagues will have to shift 
programs and support to long-term issues such as the economic impact of COVID19. Sport leagues can have a unique influence, and arguably an obligation, to drive positive economic outcomes in order for our society to return to a new normal. The inspiration theme will also develop, shifting from shelter-in-place focused communication to long-term positivity needed by fans. Leagues will likely showcase the return to competition; the resiliency of front office staff, teams, and athletes; and their commitment to providing an entertainment experience for fans regardless of barriers which might be in place. While the focus of league CSR platforms on providing cultural and economic benefit to fans is unwavering, the implementation of future CSR programs and associated communication will evolve. As noted by T. Jacobson (personal interview, April 28, 2020), “ . . . crisis breeds innovation.” This is true for not only the macro effect on professional sports, but also the way in which CSR platforms are responding to the unprecedented global health crisis.

\section{References}

Babiak, K., \& Wolfe, R. (2009). Determinants of corporate social responsibility in professional sport: Internal and external factors. Journal of Sport Management, 23(6), 717-742. doi:10.1123/jsm.23.6.717

Coombs, W.T., \& Holladay, S.J. (2002). Helping crisis managers protect reputational assets: Initial tests of the situational crisis communication theory. Management Communication Quarterly, 16(2), 165-186. doi:10.1177/089331802237233

Crimson Hexagon ForSight. (2020). Brandwatch. www.brandwatch.com

Gratch, J., Lucas, G., Malandrakis, N., Szablowski, E., Fessler, E., \& Nichols, J. (2015). GOAALLL!: Using sentiment in the world cup to explore theories of emotion. Paper presented at the 2015 International Conference on Affective Computing and Intelligent Interaction (ACII) (pp. 898-903). doi:10.1109/acii.2015.7344681

Kern, W.S. (2000). Introduction. In W.S. Kern (Ed.), The economics of sports (pp. 1-6). Kalamazoo, MI: W.E. Upjohn Institute for Employment Research for Employment Research. doi:10.17848/9780880993968.intro

Major League Soccer. (2020, May). MLS Unites: Bringing the soccer community together during COVID-19 pandemic. https://www.mlssoccer.com/mls-unites

Moran, E. (2020, April 6). NHL And MLB bringing STEM to homes of young fans. Front Office Sports. Retrieved from https://frntofficesport.com/nhl-mlb-stem-education/

National Football League. (2020, May). NFL Draft-a-thon. https://relief.nfl.com/

Stanley, M. (2020, May 9). Why the increase in domestic violence during COVID-19? Psychology Today. Retrieved from https://www.psychologytoday.com/us/blog/ making-sense-chaos/202005/why-the-increase-in-domestic-violence-during-covid-19

Wakefield, K.L., \& Wann, D.L. (2006). An examination of dysfunctional sport fans: Method of classification and relationships with problem behaviors. Journal of Leisure Research, 38(2), 168-186. doi:10.1080/00222216.2006.11950074

Zhang, Z., \& Surujlal, J. (2015). Willingness of sport fans to participate in socially responsible community programmes of professional sport organisations. South African Journal for Research in Sport, Physical Education and Recreation, 37(3), 185-197. 